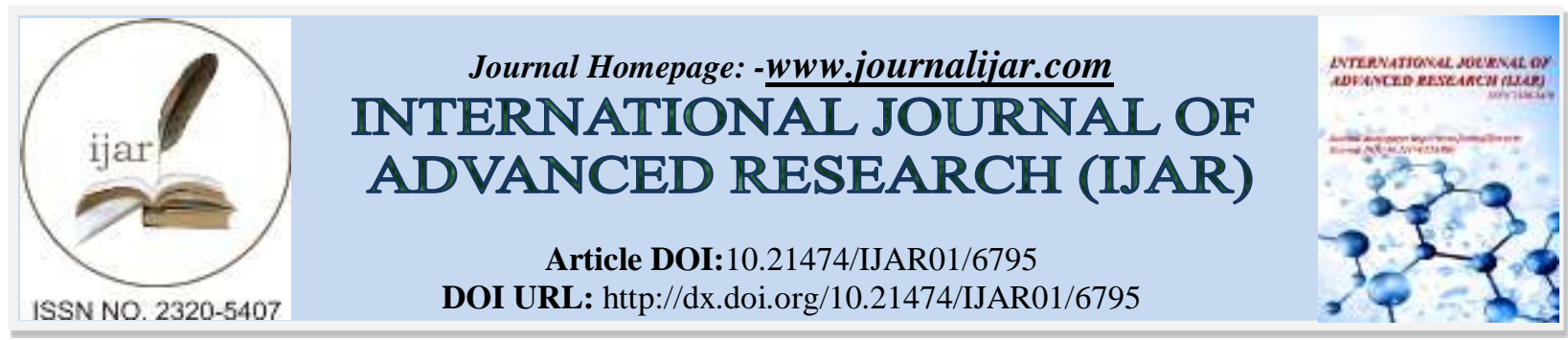

RESEARCH ARTICLE

\title{
COMPARISON OF THE HEALING POTENTIAL OF PROPOLIS AND BEE VENOM ON SURGICALLY INDUCED WOUND IN RAT'S BUCCAL MUCOSA.
}

\author{
Lina Samir Shalaby ${ }^{1}$, Ahmed Helmy Salama ${ }^{2}$, Sahar Mahmoud Shawkat ${ }^{2}$, Amira Elham Fares ${ }^{2}$ and Ahmed \\ Gaafar Hegazi ${ }^{3}$. \\ 1. Oral Biology Department, Faculty of Dentistry, Modern Sciences and Arts University (MSA), Egypt. \\ 2. Oral Biology Department, Faculty of Oral and Dental Medicine, Cairo University, Egypt. \\ 3. Oral Biology Department, Faculty of Oral and Dental Medicine, Cairo University, Egypt. \\ 4. Oral Biology Department, Faculty of Oral and Dental Medicine, Cairo University, Egypt. \\ 5. Microbiology and Immunology, National Research Center, Egypt.
}

\section{Manuscript Info}

(.........................

Manuscript History

Received: 20 January 2018

Final Accepted: 22 February 2018

Published: March 2018

Keywords:-

Bee venom, Propolis, Mucosa, Wound healing.

\section{Abstract}

Bee products include honey as well as propolis, royal jelly and venom which are used in medicine, not only as an immune system stimulant but also as a wound healing promoter. Aim of work: was to assess and compare the healing potential of propolis and bee venom on the healing wounds in rat's buccal mucosa. Materials and Methods: Foutry five adult male Wistar albino rats divided into in 3 groups of 15 each (control, propolis \& bee venom). A wound $(3.5 \mathrm{~mm}$ diameter) was made in the cheek of each rat with a punch biopsy. Samples were prepared and investigated histopathologically and immunohistochemically by proliferating cell nuclear antigen (PCNA) after 1, 3 and 7 days of wounding. Results: Bee venom showed the highest healing potential followed by propolis through stimulated epithelial cells proliferation and reepithelization compared to the control group. Conclusion: Bee venom and Propolis had contributed positively to the wound healing in the surgically induced wounds of rat's buccal mucosa.

Copy Right, IJAR, 2018,. All rights reserved.

\section{Introduction:-}

Wounds are considered unavoidable life events. Wounds may arise due to physical, chemical, or microbial effects (Ilango et al., 2010). Wound healing is a complex series events involving resident and migratory cells and the extracellular matrix (ECM). That aims for the proper restoration of normal tissues both functionally and structurally (Krafts, 2010). The wound healing process can be divided into three or four distinct phases, which are hemostasis, inflammation, proliferation and remodeling (Enoch et al., 2008; Szpaderska et al., 2003; Reinke and Sorg, 2012) Apitherapy (the term comes from the Latin Apis, which means "bee" or bee therapy, is the use of bee products for therapeutic purposes (Hegazi, 2012; Ürünlerinin et al., 2012). Propolis is a resinous material collected by bees from exudates and buds of the plants (Almeida and Menezes, 2002). Propolis has several therapeutic properties, such as antibacterial, anti-inflammatory, healing, anesthetic, anticariogenic, antifungal, antiprotozoal, anti-tumoural and antiviral activities (Banskota et al., 2001; Hegazi et al., 2014a; Hegazi et al., 2014b; Hegazi et al., 2017 ) . Bee venom (BV) is a complex mixture of proteins, peptides and low molecular components (Bogdanov, 2014). BV is a well-known pharmacologically active product of the bee hive. Due to its anti-oxidants, anti-coagulants, anti- 
inflammatory, antibacterial properties (Hegazi et al., 2015) and bioactive substances like melittin and phospholipase (Castro et al., 2005; Ram et al., 2014).

With an increasing necessity for a natural medication, the current medical treatment modalities directs attention to the natural products and biological methods to be used in the clinical practice due to the high costs and side effects of the traditional treatments (Majtan et al., 2010). The aim of the present study was to assess and compare the healing potential of propolis and bee venom on surgically induced wound on rat's buccal mucosa.

\section{Materials and methods:-}

The experimental protocol of the present study follow the recommendations and got the approval of the Ethics Committee on animal's experimentation of the Faculty of Oral and Dental Medicine, Cairo University. Propolis and bee venom were kindly obtained from Apery farm of Professor Ahmed Hegazi (National Research Center, Dokki, Giza, Egypt) during spring season 2015. For intra oral irrigation of the wound lesion, $1 \mathrm{gm}$ of the dried propolis was dissolved in $10 \mathrm{ml}$ of saline to obtain propolis extract in a form of solution, while $0.1 \mathrm{gm}$ of collected dried bee venom was freshly mixed with $10 \mathrm{ml}$ of saline solution. Saline solution only was used as a control.

\section{Animals:-}

45 adult male Wistar albino rats of average weight 150-200 grams were used from the Animal House (Faculty of Medicine, Cairo University, Egypt). Rats were housed in stainless-steel cages, 5 rats per cage. All rats were maintained on basic diet of regular rat chow and distilled water adlibitum. Rats were divided into 3 groups; each group was further subdivided into 3 subgroups according to sacrifice date as illustrated in the following table

\begin{tabular}{|l|c|c|c|}
\hline & Group C (Control) & Group P (Propolis) & Group BV (Bee venom) \\
\hline Day of the surgery & \multicolumn{3}{|c|}{ Buccal mucosal wound induction in all rats } \\
\hline No. of rats & \multicolumn{3}{|c|}{15} \\
\hline Intervention & Saline & Propolis & Bee venom \\
\hline Route & \multicolumn{3}{|c|}{ Intra oral irrigation } \\
\hline Date of sacrifice & 1,3 and 7 days \\
\hline
\end{tabular}

All animals were anesthetized with a mixture of $13 \mathrm{mg} / \mathrm{kg}$ of xylazine $(2 \%)$ and $33 \mathrm{mg} / \mathrm{kg}$ of ketamine via intramuscular injection. After anesthesia, the cheek was pulled and a wound was induced opposite to the mid buccal premolar area using sterile punch biopsy instrument $(3.5 \mathrm{~mm}$ diameter) limited to mucosal tissues without involving the muscular layer. Immediately after wound induction, for intra oral irrigation a syringe with an attached sterile metal tube was loaded either with $0.5 \mathrm{ml}$ of propolis, bee venom or saline solution and each wound lesion was irrigated for 30 seconds once daily for 7 days successively. The rat head was held in a horizontal position during irrigation to allow direct contact between the solution and the wound lesion for 30 seconds.

The animals were sacrificed with cervical dislocation after 1,3 and 7 days of treatment. The buccal mucosa containing the induced buccal wound was dissected. Each wound was excised using a $5.5 \mathrm{~mm}$ punch biopsy, maintaining approximately $2 \mathrm{~mm}$ of intact mucosa around the marked wound lesion. Then fixed in 10\% formalin solution and subjected to routine laboratory studies after sectioning at a thickness of $4 \mu$. Samples were stained with hematoxylin and eosin and immunohistochemically examined using proliferating cell nuclear antigen (PCNA) followed by histomorphometric analysis.

\section{Statistical analysis:-}

The statistical analysis was performed using the arithmetic mean, standard deviation (S.D.) and one way ANOVA with tukeys post hoc test.

\section{Results:-}

\section{Histopathological Results}

After 1 day, control group showed complete loss of epithelium and tissue fragmentation lateral to the wound lesion with heavy inflammatory cell infiltrates in the underlying connective tissue. While less inflammatory cell infiltrates in propolis group and few in bee venom group were detected. (Fig.1) 
After 3 days, control group showed incomplete epithelial rim covering the wound lesion. The sub epithelial connective tissue showed numerous scattered inflammatory cell infiltrations and dilated blood vessels engorged with blood. While in propolis the newly formed epithelial lining appeared in a form of thin continuous layer of basal and parabasal cells (with mitotic figures) that cover all the wound lesion. A thicker epithelial layer in bee venom group with moderate inflammatory cell infiltrates in the underlying connective tissue in both groups was observed. (Fig. 2)

After 7 days, the newly formed covering epithelium in the control group showed hyperkeratosis and acanthosis. The subepithelial connective tissue revealed some inflammatory cells. In propolis group, the wound was completely covered with hyperkeratotic acanthotic epithelium (but less than that of the control group) while nearly normal epithelial thickness in bee venom group was observed. The subepithelial connective tissue in both groups showed fewer inflammatory cells compared to the control group. (Fig. 3)

\section{PCNA histomorphometric results:-}

On the basis of one-way ANOVA test the image analysis of PCNA positive epithelial cells of the buccal mucosa sections after 1, 3 and 7 days demonstrated the following:

\section{After 1 Day:-}

PCNA mean percentage among the control and experimental groups showed a statistically non-significant ( $>>0.05)$ difference among the different groups (Fig.4A).

\section{After 3 Days:-}

PCNA mean percentage among the control and experimental groups showed a statistically significant difference between the control group and $\mathrm{P}$ group $(\mathrm{p}<0.05)$, a statistically significant difference between the control group and BV group $(\mathrm{p}<0.05)$ while a statistically non-significant difference between the P group and BV group ( $>0.05)$ (Fig.4B).

\section{After 7 Days:-}

Morphometric analysis showed that the BV group had the highest mean values of PCNA immunoreaction followed by P group and then the control group which had the lowest PCNA mean values. PCNA mean percentage among the control and experimental groups showed a statistically significant difference between the control group and $\mathrm{P}$ group $(\mathrm{p}<0.05)$, a statistically significant difference between the control group and BV group $(\mathrm{p}<0.05)$ and a statistically significant difference between the $\mathrm{P}$ group and BV group $(\mathrm{p}<0.05)$ (Fig.4C).

\section{Discussion:-}

Wound healing is well orchestrated process which is divided into three or four phases, which are hemostasis, inflammation, proliferation, and remodeling. These distinct, complex phases overlap in order to ensure tissue repair (Abreu et al., 2012). The aim of this study was to evaluate and compare the healing potential of Propolis and bee venom as a local treatment modality on surgically induced wound on Wistar rat's buccal mucosa. In the current study which involves the oral mucosa, rats are commonly used in relation to other animals due to the low cost, the easy manipulation and the similarity between the oral mucosa of rats and humans, the oral epithelium of rats is basically made up of epithelial tissues on the surface and subjacent connective tissue (Cavalcante et al., 2011). Propolis is believed to be a useful product for wound healing and is already used in alternative medicine. It contains a wide-range of chemical compounds that have many biological activities such as, antioxidant, anti-inflammatory and immunomodulatory activities (Kosalec et al., 2004; Savickas et al., 2005). Bee venom comprises a very complex mixture of active peptides, enzymes and amines such as melittin, phospholipase A2, apamin and Adolapin. These substances demonstrated significant antinociceptive, anti-inflammatory, antibacterial effects and immunity boosting action. The therapeutic application of bee venom has been used in the traditional medicine to treat different diseases (Hegazi et al., 2014c).

The healing process was evaluated at three time intervals; one, three and seven days after wound induction. According to literature reviews these time slots were the most commonly used to monitor tissue changes occurs during wound healing process (Hashemipour et al., 2012; Han et al., 2011).

Histological examination of the specimens of the control group one day after wound induction revealed heavy inflammatory cells infiltration in the sub epithelial connective tissues. These results were in agreement with the 
work of Hashemipour et al., (2012) where the polymorphonuclear leucocyte (PMNL) cell infiltrates recorded the highest inflammation score on the second day in the Control group.

In the current study, histological examination of the wound lesion treated with propolis $(\mathrm{P})$ solution, after 1 day, showed less inflammatory cells in the connective tissue beneath the wound. As propolis displays anti-inflammatory properties in both acute and chronic inflammatory processes, and this is principally due to its large content of polyphenol compounds this is supported with Martinotti and Ranzato (2015b).These findings were in agreement with Martin et al., (2013) who reported few neutrophils at 24 and 48 hours in response to silver nitrate-induced corneal ulcer in rats that was topically treated with a micro emulsion containing $1 \%$ Brazilian propolis.

On the other hand, histological examination of the wound lesion treated with bee venom (BV) solution after 1 day showed less inflammatory cells in the connective tissue beneath the wound. This could be due to the antiinflammatory properties of bee venom. Our results could be in agreement with Park et al., (2007) who claimed that BV reduced carrageenan-induced inflammation through the inhibition of PG (prostaglandin) E2 generation, which are synthesized systemically in inflammatory diseases as shown in animal models of arthritis.

Histological samples of the control group after 3 days, showed beginning of re-epithelization in the form incomplete rim of basal and parabasal cells and numerous inflammatory cells in the subepithelial connective tissue. While, Histological samples of propolis 3 days showed coverage of the wound lesion with a reorganized epithelial layer of basal and parabasal cells with mitotic figures with less inflammatory cells in the underlying lamina proporia. These results were in accordance with Berretta et al., (2012) who created a skin lesion using a punch in the back of the rat then treated with saline (control group) or propolis. They reported start of the healing process 3 days after wounding in the control group while closure of the punctured wounds in the group treated with propolis. Anti-inflammatory and wound healing properties of propolis were mainly attributed to the presence of flavonoids and phenolic compounds (Borrelli et al., 2002). That appear to be responsible for the contraction of the lesion and the increased rate of epithelialization (Nayak et al., 2006).

After 3 days following wound induction and BV application, wound size was markedly decreased with closure of the wound lesion with continuous thick layer of epithelium in the form of basal and Parabasal cells. The newly formed epithelial layer was thicker and with higher mitotic basal and parabasal figures than that formed in the propolis group after 3 days. The subepithelial connective tissue revealed reduction in inflammatory cell infiltrates. These findings were in accord with Han et al., (2011) Who found that the BV demonstrated accelerated wound contraction and reepithelialization thus the wound size decreased dramatically.

These results could be due to BV content of mast cell degranulating peptide (MCD) that lyses mast cells, releasing histamine, serotonine and heparine that causing increased capillary permeability and anti-inflammatory action. Also histamine is one of the major components which dilates blood vessels, increasing the permeability of blood capillaries and increases blood circulation (Moreno and Giralt, 2015).

After 7 days from wound induction, the healing of the control group was obtained by regeneration of the epithelium, wound was decreased in size and was covered with acanthotic and hyperkeratotic layer of epithelium. The intense inflammation was decreased with presence of few inflammatory cells in the underlying lamina propria. These findings were in agreement with Fahim et al., (2016) who created a circular wound of $3.0 \mathrm{~mm}$ diameter on the buccal mucosa of wistar rats. On post-wound day 7, they observed a prominent increase in the thickness of the regenerating epithelium with fibroblasts, collagen fibers, blood vessels, and inflammatory cells in the underlying lamina propria.

Oxidative stress has been implicated in a variety of degenerative processes and diseases. These mainly include acute and chronic inflammatory conditions like wound healing (Maier \& Chan, 2002). Propolis possessed antioxidant properties depending mainly on its flavonoids' content. It also induced the activation of antioxidant enzymes such as catalase and superoxide dismutase against free radicals (Jasprica et al., 2007). Flavonoids in the propolis are potent antioxidant, capable of scavenging free radicals and thereby protecting the cell membrane against lipid peroxidation that help in healing of wounds (Daleprane and Abdalla, 2013).

In the present study after 7 days, Histological samples of propolis showed the closure of the wound lesion with a reorganized epithelial layer where epithelial cells showing a few number of mitotic figures. Presence of fibroblasts 
and organized collagen fibers with less inflammatory cells in the completely reconstructed lamina proporia. From this findings we suggested that propolis stimulate cell proliferation and tissue repair. These results were supported by Berretta et al., (2012) who used wistar rats with puncture wounded skin to evaluate the wound healing properties of propolis. They reported epithelization seven days after the injury, where the collagen fibers were completely reconstituted and a reorganization of the epithelial layer was observed.

Complete reepithelization was accomplished in bee venom group, 7 days after wound induction. By this time histological samples revealed the structure of the subepithelial connective tissue and collagen fibers, which provide support to the tissue are completely reconstituted with fibroblasts. Presence of few inflammatory cell infiltrates was also accidently recorded. A reorganization of a thick epithelial layer was observed where epithelial cells showing a large number of mitotic figures, a process that culminates with the closing of the injury. That may be due to stimulation of cell proliferation and wound healing improvement associated with bee venom treatment. These results were in agreement with Han et al. (2011) Who claimed that bee venom augmented wound healing with concomitant inhibition of cytokines associated with fibrosis, which resulted in decreased wound size and increased epithelial proliferation in a mouse full-thickness excision wound model.

Proliferating cell nuclear antigen (PCNA) is a well-known marker of cell proliferation. PCNA plays an important role in DNA synthesis, DNA repair, cell cycle progression and cell proliferation (Chiang et al., 2000). The immunohistochemical results of the ongoing research have revealed the greatest PCNA expression was in bee venom group followed by propolis with the least PCNA expression in control group. The higher PCNA expression in the BV group followed by propolis indicated the presence of great number of proliferative epithelial cells during regeneration.

Little number of proliferating epithelial cells were found and showed weak PCNA immunoreaction in the control group after 3 days. These results could be correlated with those of Saad et al., (2015) who found few weak positively reactant epithelial cells in the tissues of Nicorandil- induced labial ulcer in rats of the control group on the third day.

Epithelial cells covering the wound lesion in the propolis and the bee venom groups exhibited strong positive immunoreaction for PCNA after the third day, indicating the presence of proliferative cells which started to appear after treating the lesion with propolis or bee venom.

After seven days of the lesion, specimens of the control group showed mild immunoreactions of PCNA in few basal cells. Our result correlated with Beckert et al., (2004) who revealed mild immunoreactions of PCNA in few epithelial and connective tissue cells at the gastric ulcer margin induced with a cryoprobe (blunt chilled instrument used to freeze tissues in cryosurgery) in control group of male rats after seven days of ulcer induction.

In the current study, epithelial cells showed moderate to strong positive PCNA immunoreactivity after 7 days of lesion treatment with propolis. Propolis could trigger the maturation of the proliferating keratinocytes. As, Propolis contains active compounds which are known to promote cell proliferation or apoptosis. Among them, there are caffeic acid, caffeic phenyl ester, artepillin C, quercetin, resveratrol, galangin, and genistein ( Zhang et al., 2009; Ha et al., 2013).

7 days after treatment of the lesion with bee venom, the buccal mucosa sections revealed increased number of PCNA positive cells in the newly formed epithelium. We suggested that the higher proliferative expression of PCNA in BV group could be attributed to that the BV could enhance epithelial cells proliferation.

\section{Conclusion:-}

Both bee venom and propolis could enhance wound healing through stimulation of epithelial cells proliferation thus increasing the reepithelization, improve wound closure and decreasing inflammation (as prolonged inflammation and inflammatory cytokines release might cause damage to the tissues). Based on the limitation of the present study. Bee venom was proved to have the highest healing potential followed by propolis then saline (control).

\section{Acknowledgement:-}

I dedicate this work to the soul of my dear professor Ahmed Helmy, the completion of this work wouldn't have become possible without his vast knowledge and ample experience. Also I would like to thank A. professor 
Mohamed Shamel and A. professor. Hany Khattab for their guidance and help. Finally, I would like to extend my gratitude to my precious family especially my mother and my exquisite friends for their continuous encouragement and support.

Declaration of Interest:-

The authors report no conflict of interest and the article is not funded or supported by any research grant.
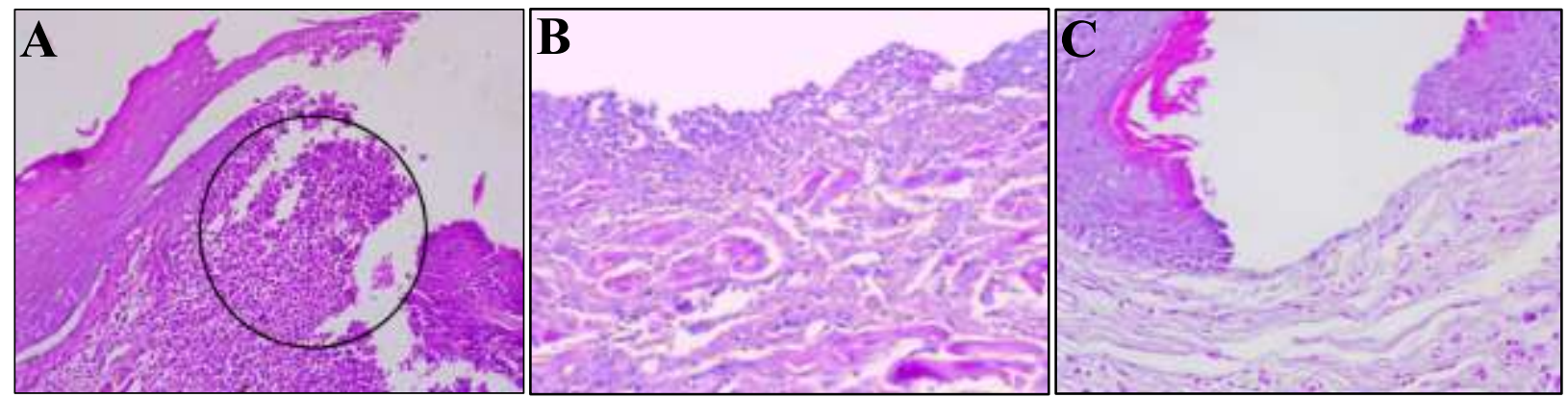

Fig.1 photomicrographs of the histologic section of the wounds after 1 day. The rat's buccal mucosa sections were stained with Hematoxylin and Eosin stain (200x). (A) The control group showing epithelial tissue fragmentation lateral to the wound lesion with heavy inflammatory cell infiltrate in the underlying connective tissue, While (B) The propolis group showing less inflammatory cell infiltrates and (C) The bee venom group showing few inflammatory cells.
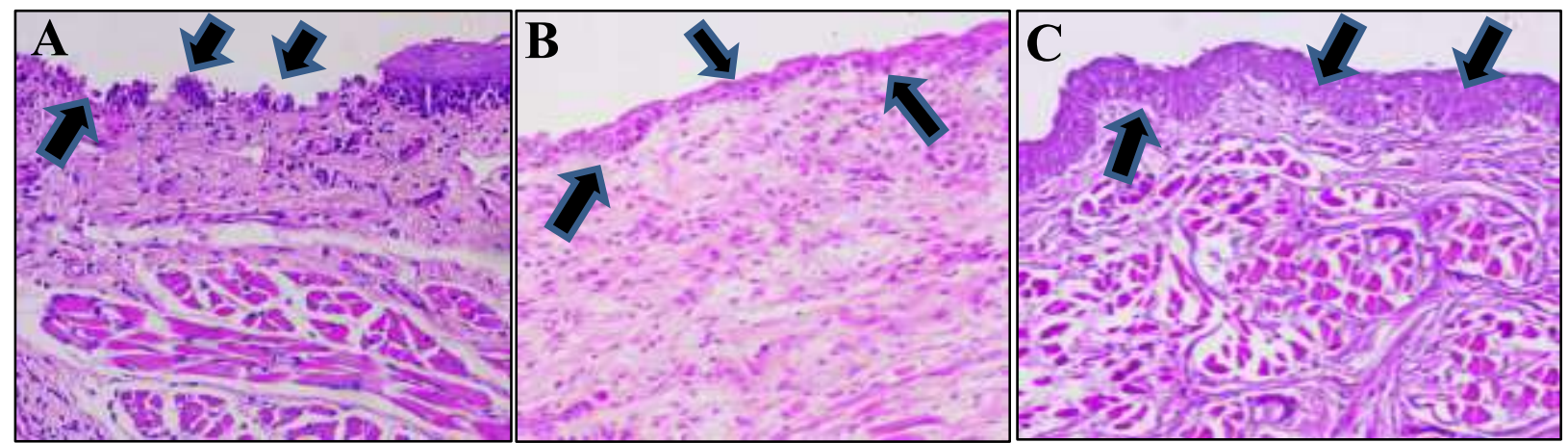

Fig.2 photomicrographs of the histologic section of the wounds after 3 days. The rat's buccal mucosa sections were stained with H\&E stain (200x). The newly formed epithelial layer (A) In the control group is thin and incomplete rim of basal and parabasal cells (black arrows), numerous scattered inflammatory cells, dilated blood vessels engorged with blood. While (B) In the propolis group it is thick and continuous epithelium (black arrows). And (C) In the bee venom group it is continuous but thicker than that in the propolis group (black arrows). With moderate inflammatory cell infiltrates were observed in both groups (B \& C).
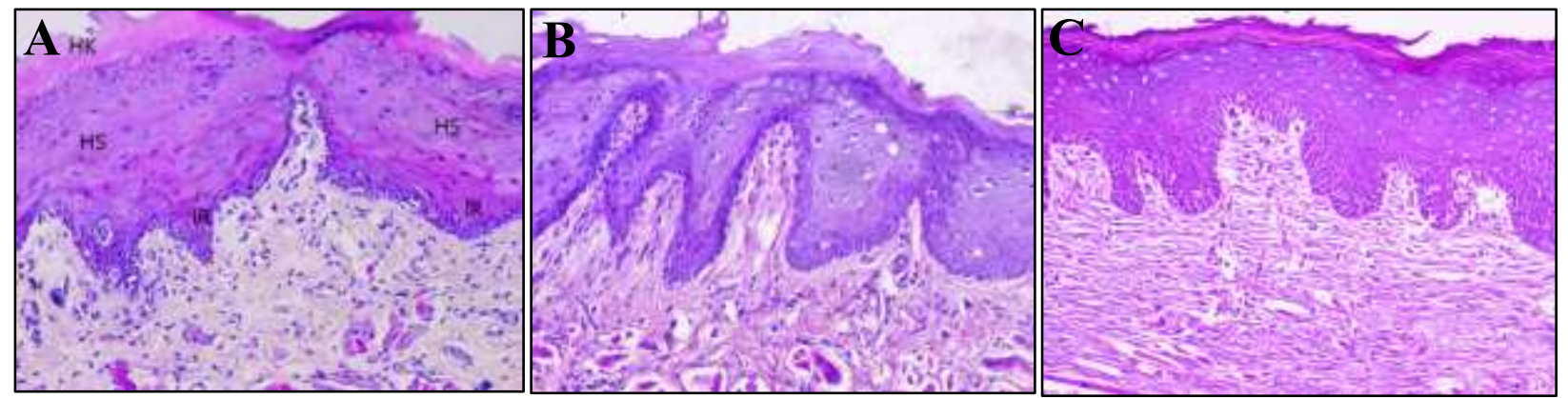

Fig.3 photomicrographs of the histologic section of the wounds after 7 days. The rat's buccal mucosa sections were stained with Hematoxylin and Eosin stain (200x). All wounds were covered with epithelium (A) The control group showing hyperkeratotic (HK), acanthotic (HS) epithelium with irregular rete pegs (IR) and some inflammatory cells in the underlying lamina propria. (B) The propolis group showing hyperkeratotic and acanthotic epithelium. (C) The 
bee venom group showing epithelial thickness near to the normal. And fewer inflammatory cells were observed in both groups $(\mathrm{B} \& \mathrm{C})$ compared to the control group.

A

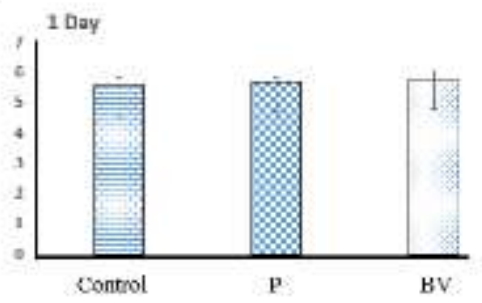

C

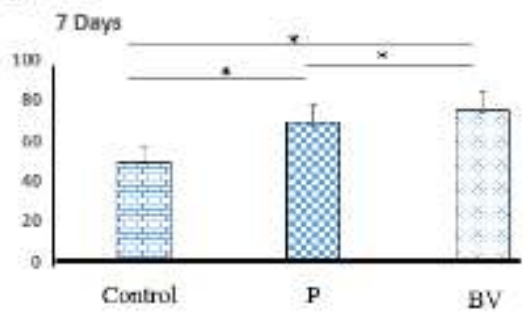

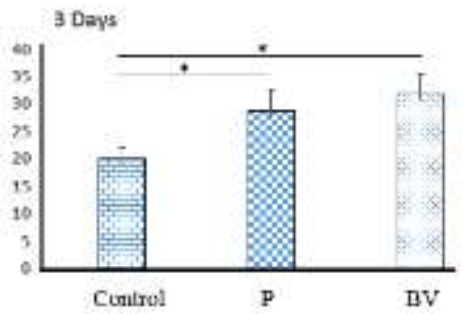

Fig.4 graphs showing PCNA mean percentage of the three different groups after 1, 3 and 7 days.

\section{References:-}

1. Abreu, A. M., Douglas de Oliveira, D. W., Marinho, S. A., Lima, N. L., de Miranda, J. L., \& Verli, F. D. (2012). Effect of topical application of different substances on fibroplasia in cutaneous surgical wounds. ISRN Dermatology, 282973.

2. Almeida, E. C. D., \& Menezes, H. (2002). Anti-inflammatory activity of propolis extracts: a review 2104. Journal of Venomous Animals and Toxins, 8, 191-212.

3. Banskota, A. H., Tezuka, Y., \& Kadota, S. (2001). Recent progress in pharmacological research of propolis. Phytotherapy Research.

4. Beckert, S., Class, N., Farrahi, F., \& Coerper, S. (2004). Growth hormone enhances gastric ulcer healing in rats. Medical Science Monitor: International Medical Journal of Experimental and Clinical Research, 10(8), BR255-8.

5. Berretta, A. A., Nascimento, A. P., Bueno, P. C. P., Leite Vaz, M. M. de O. L., \& Marchetti, J. M. (2012). Propolis standardized extract (EPP-AF), an innovative chemically and biologically reproducible pharmaceutical compound for treating wounds. International Journal of Biological Sciences, 8(4), 512-521.

6. Bogdanov, S. (2014). "Bee Venom : Composition, Health, Medicine : A review bee venom in history".no. February: $1-20$.

7. Borrelli, F., Maffia, P., Pinto, L., Ianaro, A., Russo, A., Capasso, F., \& Ialenti, A. (2002). Phytochemical compounds involved in the anti-inflammatory effect of propolis extract. Fitoterapia, 73(SUPPL. 1).

8. Cavalcante GM, Sousa de Paula RJ, Souza LP, Sousa FB, Mota MR and Alves AP. Experimental model of traumatic ulcer in the cheek mucosa of rats. Acta Cir. Bras. 2011, 26(3):227-234.

9. Castro, H. J., Mendez-Lnocencio, J. I., Omidvar, B., Omidvar, J., Santilli, J., Nielsen, H. S., Bellanti, J. A. (2005). A phase I study of the safety of honeybee venom extract as a possible treatment for patients with progressive forms of multiple sclerosis. Allergy and Asthma Proceedings, 26(6), 470-6.

10. Chiang, C. P., Lang, M. J., Liu, B. Y., Wang, J. T., Leu, J. S., Hahn, L. J., \& Kuo, M. Y. P. (2000). Expression of proliferating cell nuclear antigen (PCNA) in oral submucous fibrosis, oral epithelial hyperkeratosis and oral epithelial dysplasia in Taiwan. Oral Oncology, 36(4), 353-359.

11. Daleprane, J. B., \& Abdalla, D. S. (2013). Emerging roles of propolis: Antioxidant, cardioprotective, and antiangiogenic actions. Evidence-Based Complementary and Alternative Medicine.

12. Enoch, S., Moseley, R., Stephens, P., \& Thomas, D. W. (2008). The oral mucosa: A model ofwound healing with reduced scarring. Oral Surgery.

13. Fahim, A., Ilyas, M. S., Jafari, F. H., \& Farzana, F. (2016). Effect of carbonated drinks on wound healing of oral epithelium. Journal of Oral Biology and Craniofacial Research, 6(1), 50-54.

14. Ha, T. K., Kim, M. E., Yoon, J. H., Bae, S. J., Yeom, J., \& Lee, J. S. (2013). Galangin induces human colon cancer cell death via the mitochondrial dysfunction and caspase-dependent pathway. Experimental Biology and Medicine (Maywood, N.J.), 238(9), 1047-54. 
15. Han, S., Lee, K., Yeo, J., Kim, W., \& Park, K. (2011). Biological effects of treatment of an animal skin wound with honeybee (Apis melifera. L) venom. Journal of Plastic, Reconstructive and Aesthetic Surgery, 64(3).

16. Hashemipour, M. A., Ghasemi, A. R., Dogaheh, M. A., \& Torabi, M. (2012). Effects of Locally and Systemically Applied n-3 Fatty Acid on Oral Ulcer Recovery Process in Rats. Wounds: A Compendium of Clinical Research and Practice, 24(9), 258-66.

17. Hegazi A. G. Al Guthami, F. M, Al Gethami AF. M. and Barakat A M. (2017): Egyptian Propolis 12: Influence of Propolis on Cytokines of Toxoplasma gondii Infected Rats. Int.J.Curr.Microbiol.App.Sci. 6 (5): 202-211

18. Hegazi A.G., EL-Feel M. A., Eman H. Abdel-Rahman and Abed Al-Fattah M. A. (2015): Antibacterial activity of bee venom collected from Apis mellifera Carniolan pure and hybrid races by two collection methods. Int. J. Curr. Microbiol. App. Sci, 4(4): 141-149.

19. Hegazi A.G., Al Tahtawy R. H.M., Abdou A. M. and Abd Allah F. (2014a): Egyptian propolis 10: It's effect on hematological changes and bacterial load in mice-bearing Ehrlich Ascites Carcinoma and concurrently infected with Staphylococcus aureus . Academic Journal of Cancer Research 7 (3): 215-223.

20. Hegazi A.G., Abdou A. M. and Abd Allah F. (2014b): Egyptian Propolis 1I: Antimicrobial activity with comparison with deferent localities. Int.J. Curr.Microbiol.App.Sci 3(9) 530-538.

21. Hegazi, A., Abdou, A. M., El-Moez, S. I., \& Allah, F. A. (2014c). Evaluation of the antibacterial activity of bee venom from different sources. World Applied Sciences Journal, 30(3), 266-270.

22. Hegazi A.G. (2012): Medical importance of bee products. ARI BILIMİ / BEE SCIENCE 12(4): 136-146.

23. Ilango, K., Prakash Yoganandam, G., Usha, K., Priyanga, K. S., Ilansezhiyan, M., \& Kalaiarasi, V. (2010). Evaluation of wound healing activity of hexane and methanolic extract of fruit pulp of Momordica balsamina Linn in albino rats. International Journal of Pharmacy and Pharmaceutical Sciences, 2(1), 88-92.

24. Jasprica, I., Mornar, A., Debeljak, Ž., Smolčić-Bubalo, A., Medić-Šarić, M., Mayer, L., Šverko, V. (2007). In vivo study of propolis supplementation effects on antioxidative status and red blood cells. Journal of Ethnopharmacology, $110(3), 548-554$.

25. Kosalec, I., Bakmaz, M., Pepeljnjak, S., \& Vladimir-Knezević, S. (2004). Quantitative analysis of the flavonoids in raw propolis from northern Croatia. Acta Pharmaceutica (Zagreb, Croatia), 54(1), 65-72.

26. Krafts, K. P. (2010). Tissue repair: The hidden drama. Organogenesis, 6(4), 225-33.

27. Maier, C.M.\& Chan, P.H.(2002): Role of superoxide dismutases in oxidative damage and neurodegenerative disorders. Neuroscientist 8:323-334.

28. Majtan, J., Kumar, P., Majtan, T., Walls, A. F., \& Klaudiny, J. (2010). Effect of honey and its major royal jelly protein 1 on cytokine and MMP-9 mRNA transcripts in human keratinocytes. Experimental Dermatology, 19(8).

29. Martin, L. F. T., Rocha, E. M., Garcia, S. B., \& Paula, J. S. (2013). Topical Brazilian propolis improves corneal wound healing and inflammation in rats following alkali burns. BMC Complementary and Alternative Medicine, 13, 337.

30. Martinotti, S., \& Ranzato, E. (2015). Propolis: a new frontier for wound healing? Burns \& Trauma, 3, 9.

31. Moreno, M., \& Giralt, E. (2015). Three valuable peptides from bee and wasp venoms for therapeutic and biotechnological use: Melittin, apamin and mastoparan. Toxins.

32. Nayak, S., Nalabothu, P., Sandiford, S., Bhogadi, V., \& Adogwa, A. (2006). Evaluation of wound healing activity of Allamanda cathartica. L. and Laurus nobilis. L. extracts on rats. BMC Complementary and Alternative Medicine, 6(1), 12.

33. Park, H. J., Son, D. J., Lee, C. W., Choi, M. S., Lee, U. S., Song, H. S., ... Hong, J. T. (2007). Melittin inhibits inflammatory target gene expression and mediator generation via interaction with IкB kinase. Biochemical Pharmacology, 73(2), 237-247.

34. Ram, S. K. M., Jayapal, N., Nanaiah, P., Aswal, G. S., Ramnarayan, B. K., \& Taher, S. M.(2014). The therapeutic benefits of bee venom. Int. J. Curr. Microbiol. App. Sci, 3(11), 377-381.

35. Reinke, J.M.\& Sorg, H. (2012). Wound Repair and Regeneration, 35-43.

36. Saad, A. E., Elbaz ,D. \& Bashir, M. (2015). A Comparative Study on the Healing Potential of Induced Labial Ulcerative Defects Treated with Nanosilver and Chlorhexidine. Nature and Science, 13(11).

37. Savickas, A., Majiene, D., Ramanauskiene, K., Pavilonis, A., Muselik, J., Masteikova, R., \& Chalupova, Z. (2005). Chemical composition and antimicrobial activity of Lithuanian and Czech propolis. BIOLOGIJA, (4), 59-63.

38. Szpaderska, A. M., Zuckerman, J. D., \& DiPietro, L. A. (2003). Differential Injury Responses in Oral Mucosal and Cutaneous Wounds. Journal of Dental Research, 82(8), 621-626.

39. Ürünlerinin, A., Önemi, T., \& Hegazi, A. G. (2012). Medical Importance of Bee Products. Kasim U Bee J. November, 12(4), 136-146.

40. Zhang, Q., Zhao, X.-H., \& Wang, Z.-J. (2009). Cytotoxicity of flavones and flavonols to a human esophageal squamous cell carcinoma cell line (KYSE-510) by induction of G2/M arrest and apoptosis. Toxicology in Vitro, 23(5), 797-807. 